\title{
MAY THE SEA-BATTLE TOMORROW NOT HAPPEN?
}

\begin{abstract}
This note provides a review of the book 'On the Sea-Battle Tomorrow That May Not Happen' by Tomasz Jarmużek.

Keywords: Aristotle, future contingents, structure of time.

The headline question is a pivotal problem of a book entitled 'On the SeaBattle Tomorrow That May Not Happen' [5]. ${ }^{1}$ The aim of the monograph is to reconstruct and analyze the reasoning of the Megarian philosopher and logician, Diodorus Cronus. Unfortunately, the knowledge about his considerations is highly uncertain and fragmentary, nevertheless, it can be inferred from some, not only historical sources that Diodorus Cronus have plunged into a polemic with Aristotle. Stagyrite announced the problem of the logical value of sentences about the future by raising a question that became the inspiration for the book's title: Will be a sea-battle tomorrow? In response, Diodorus Cronus proposed a reasoning that went down in history as the Master Argument. The author reconstructs its form by means of modern logic in five different ways. The polemics between philosophers resulted from their approaches - Aristotle as an indeterminist argued that sentences about future are not necessary and moreover he adopted the principle of bivalence. In contrast to him, Diodorus Cronus approach has been regarded as deterministic. One of the fundamental issues in the monograph
\end{abstract}

\footnotetext{
${ }^{1}$ It is an English and improved version of the Polish book 'Jutrzejsza bitwa morska. Rozumowanie Diodora Kronosa' that was published six years ago [4].
} 
is to analyze whether Master Argument factually forces the linear structure of time, which is a differentiator of determinism. Although Diodorus Cronus reasoning is a major problem of philosophy that has been studied multiple times, e.g. by such philosopher as Jakko Hintikka [3], the book under review provides a new fresh approach to the problem. Even though already existing reconstructions of the problem appear in the book, the author analyzes them in an inventive way.

The work consists of three parts. The first part is the introduction, where the first chapter concerns the ancient dispute about definitions of modality and the status of sentences about the future. The issue itself has been formulated by Aristotle in the Chapter 9 of 'On Interpretation' [1], where he considers the problem of the necessity or impossibility of tomorrow's sea battle. According to Aristotle, we cannot make assertion that something will happen until it actually happens. As opposed to this view, Diodorus Cronus claims that the expressions referring to the future events could bear a logical value. What is significant, chapter one outlines three essential terms that shape the frame of the problem: determinism, time and truth, discussed in following chapters.

The second chapter is an attempt to present the notion of language in the context of the notion of time. Nevertheless it is not a comprehensive discussion, but it is justified by further analysis, which does not require such an extensive exploration. In this chapter, the role of the meaning of the sentences is emphasized. The author makes a historical review of the issue, referring to philosophers such as Willard Van Orman Quine or Gottlob Frege. The relationship between the sentence and the proposition is underlined, inclining towards an objectivist approach, represented by Frege, where the proposition is the meaning expressed by the sentence. Attention is drawn to pragmatic component of the statement and sentences that are temporarily determined, making them context invariant.

Then, the most important concepts of truth employed in monograph are discussed. They are divided into the epistemic concepts and the nonepistemic concepts of truth. What is important, the study mainly takes into account non-epistemic concepts of truth, based on a belief that logical value does not depend on the cognising subjects. This limitation is justified by the composition of the study and the narrative conducted in it. Subsequently, the Tarski's concept of truth is distinguished, which is further modified by limiting domain of sentences to sentences that are temporarily 
determined. The problem of bivalence of sentences and dynamics of logical values in the context of determinism and indeterminism is discussed.

The third chapter presents the problem of determinism. The ontological, physical and metaphysical determinism is discussed and the consequences of determinism in the form of logical, epistemological, temporal and anthropological determinism are emphasized. In the context of Diodorus Kronos reasoning, the temporal determinism is accented, a concept according to which, if the world is determined, there exists only one correct description of the future. At the end of the chapter branching and linear structures of time are presented. They are discussed in the following part of monograph.

The next chapter discusses the subject of time. Any use of term 'time' equips this concept with a different meaning. Therefore, the reasoning about time is briefly discussed from many perspectives - cultural, psychological, phenomenological and physical. Next, the author moves on to philosophy of time and its problems, limiting considerations in an intentional way. The purpose of reviewing chosen view is not a comprehensive analysis, aimed at finding solutions, but only emphasizing the problematic issues in this area. Problems related to ontological autonomy from physical world, or those related to the passage of time [2] are accentuated. The monograph excludes the possibility of the passage of time with an undefined direction, which is justified by the necessity to take into account the past and the present time. The nomological and idiographical character of time is therefore not considered. Then, the problem of McTaggart is presented, in which he argues in favor of the thesis that time is not something real. The question of time is also associated with Diodorus Cronus resoning. Since there are not many testimonies about his views or philosophy, in the monograph the attention is mainly focused on the formal aspects of the approach to time. The aim is to reach a compromise, which was named 'formal-ontological approach to the time' and in which the set-theoretical tools are used. The considerations are limited to the so-called 'pointwise concept of time' [5, p. 125].

In the second part entitled 'The issues', there is a discussion about the origin of the problem of tomorrow's sea-battle. Problems related to modalities in Aristotle's view are highlighted and then his reflections are placed as polemical with regard to Diodorus Cronus considerations. The reasoning of Diodorus Cronus is presented as a trilemma with the following form [5, p. 147]: 
1. that everything past must of necessity be true;

2. that an impossibility does not follow a possibility;

3. and that a thing is possible which neither is nor will be true.

Owing to the fact that contradiction occurs between these three propositions, Diodorus Cronus postulated to reject the third premise, which would allow to achieve some version of logical determinism and it was related to his philosophical orientation. Nonetheless, the approach of other philosophers differed from the one adopted by Diodorus Cronus and the problem remained open. Then, the issue of futura contingentia and interesting approach to time, called the logics of branching time is raised. In the theory RDC (Reasoning of Diodorus Cronus) allowing branching, determinism would not be sine qua non condition - this problem is studied later in the monograph.

The sixth chapter deals with dates, since the understanding of the dates and their inclusion in a certain metrological system is necessary to establish the logical value of sentences. Denotations of dates are called intervals, which in turn refers to states of affairs. Some of these states can be broken down into simpler states of affairs (more detailed) and if we define logical values for sentences concerning points, we are able to determine a logical value for sentences which refer to the larger interval that these sentences refer to.

In the next section, formal issues are presented. After presenting the most important facts regarding the adopted notation, various types of temporal logics are described. It is noted that the classical logic is a theory of the classical functors and the temporal logics are theories of the temporal functors [5, p. 173]. Next, attention is dedicated to the most important concepts, useful in further research on the problem of determinism in the light of RDC. Finally, the tense logic is described, which is the logic of the sentences undetermined in time. Also some ideas of positional logics are work out in the book. The application of positional logic (a logic of realization operator) are based on former papers [6] and [7]. It results in a new kind of positional logic $\mathcal{R}_{n}^{+}$with calculations on a metric time.

The last part entitled 'Solutions' deals with possible factors of the problem of determinism (in RDC). Different reconstructions of the Master's Argument are discussed. The first of the presented reconstructions is the reconstruction elaborated by F. S. Michael, where among others, calculation of moments are presented. Then, the author works out Rescher's 
reconstruction which include interpretation of the method proposed by Zeller (the second interpretation of the premise number two). All these reconstructions are described in the chapter 'Reconstructions with operator R'. In the next chapter entitled 'Other reconstructions' reconstruction of A. N. Prior and P. Øhstrøm are presented. Within most of these reconstructions (apart from Reserch's reconstruction), it turns out that Diodorus Cronus reasoning does not necessarily leads to determinism.

The monograph has many advantages - it has a coherent structure, it is written in an accessible language and has the extensive bibliography, however, its greatest merit is originality. The author not only presents the original solution to the problem of determinism, but also makes it possible to look at the problem from a wider, also historical, perspective. The main result in the monograph is that Master's Argument, with certain interpretations, does not have to be deterministic, which means it can be reconstructed without assumption of linear time structures. Thus, despite the universal agreement on the deterministic orientation of Diodorus Cronus, its reasoning can be reconstructed in an indeterministic way. Indirectly, this monograph also presents the power of temporal logic as a tool for formal analysis of philosophical problems. The book is worth recommending to both logicians who want to deepen their philosophical knowledge and philosophers who want to get to know the power of formal methods for analyzing philosophical problems.

\section{References}

[1] Aristotle, On Interpretation, E. M. Edghill (trans.), [in:] W. D. Ross and J. A. Smith (eds.), The Works of Aristotle, Vol. 1, Oxford University Press, London (1996), pp. 46-79.

[2] M. Bunge, Philosophy of Science, Vols. 1 and 2, Transaction Publisher, New Brunswick/London (1998).

[3] J. Hintikka, Aristotle and the 'Master Argument' of Diodorus, American Philosophical Quarterly, Vol. 1(2) (1964), pp. 101-114.

[4] T. Jarmużek, Jutrzejsza bitwa morska. Rozumowanie Diodora Kronosa, Wydawnictwo Naukowe Uniwersytetu Mikołaja Kopernika, Toruń (2013). 
[5] T. Jarmużek, On the Sea-Battle Tommorow That May Not Happen. A Logical and Philosophical Analysis of the Master Argument, Peter Lang, Berlin (2018).

[6] T. Jarmużek, Minimal Logical Systems with R-operator: Their Metalogical Properties and Ways of Extensions, [in:] J. Béziau and A. Costa-Leite (eds.), Perspectives on Universal Logic, Polimetrica Publisher, Italy (2007), pp. 319-333.

[7] T. Jarmużek, A. Pietruszczak, Completenes of minimal positional calculus, Logic and Logical Philosophy, Vol. 13 (2004), pp. 147-162.

Nicolaus Copernicus University

Faculty of Humanities

Toruń, Poland

e-mail: bozena.pieta95@gmail.com 